\title{
Acute Pulmonary Vascular Talcosis: Mimicking Acute Pulmonary Embolism
}

Nandavaram S*, Chandrasekar VT and Savici D

State University of New York Upstate Medical University, Syracuse, USA

\begin{abstract}
Intravenous injection of powdered tablets intended to oral use is a common practice among drug abusers, given the greater effectiveness attributed to accelerate delivery of the drug through this route compared to oral intake. This can result in both acute and chronic changes in the pulmonary vessels and parenchyma. Various terms have been used to describe this entity and include self-induced pulmonary granulomatosis, pulmonary antithrombotic granulomatosis, pulmonary mainline granulomatosis, and angiocentric systemic granulomatosis. Acute right ventricular failure is a life threatening complication from intravenous injection of powdered medications and very few such cases have been reported in the literature.
\end{abstract}

Keywords: Talcosis; Pulmonary hypertension; Hypertension; Acute RV failure

\section{Introduction}

Sudden cardiac death secondary to intravenous drug abuse is an under diagnosed life threatening complication $[1,2]$. Here we present a case of acute pulmonary intravascular talcosis resulting in acute cardiogenic shock, right ventricular failure and death (Figure 1).

\section{Case Presentation}

30-year-old male with medical history significant for intravenous drug abuse presented to emergency room with complaints of fever chills and back pain. At the time of presentation he was afebrile, blood pressure was $132 / 76 \mathrm{~mm} \mathrm{Hg}$, pulse was 95 , and respiratory rate 16 and oxygen saturation was $96 \%$ on room air. Physical exam was significant for tenderness to palpation in the paraspinal area. Diagnostic work up was significant for white blood cell count 15.5. Echocardiogram was within normal limits. Blood cultures were positive for MRSA. MRI thoracic spine revealed infiltrative process in the dorsal epidural space from T6-T7 down to T10 level with inhomogeneous enhancement and mass effect on the spinal cord at T8 and T9 levels representing a phlegmon. Patient was started on intravenous antibiotics. IR guided aspiration of the epidural lesion was unsuccessful and the decision was made to treat him with intravenous vancomycin for a total of 6 weeks and then to follow up with imaging. Given the history of drug abuse, the patient was not discharged home and was receiving intravenous antibiotics in the hospital.

Five weeks into the hospitalization, the patient was found injecting "drugs". $48 \mathrm{hrs}$ later he developed sudden onset chest pressure, had elevated troponin and was diagnosed with non-ST segment elevation myocardial infarction. Repeat echocardiogram showed severe RV systolic enlargement and dysfunction along with paradoxical septal motion of inter- ventricular septum. Estimated pulmonary artery systolic pressure was severely increased. Few hours later the patient's oxygen requirements increased and his mental status worsened. Subsequently he was transferred to ICU.

Diagnostic work up at the time of transfer to ICU revealed WBC 27.2, $\mathrm{Hb} 10.1 \mathrm{~g} / \mathrm{dl}$, Platelet count of 33, potassium $5.6 \mathrm{mEq} / \mathrm{L}, \mathrm{Hco} 310$ $\mathrm{mEq} / \mathrm{L}$, Creatinine $1.4 \mathrm{mg} / \mathrm{dl}$, elevated liver enzymes: ALT $2890 \mathrm{IU} / \mathrm{L}$, AST $3426 \mathrm{IU} / \mathrm{L}$, Trop 0.89, Urine toxicology positive for opiates and tricyclics, INR 6.17 , fibrinogen $<60$, D-dimer $>20$, procalcitonin 0.42 , heparin induced anti platelet antibody negative, HIV negative, blood cultures were negative. Despite receiving maximal medical support with pressors, fluids, empiric antibiotics, the patient had PEA arrest. He was resuscitated with return of spontaneous circulation. However, he had multiple episodes of PEA requiring resuscitation and subsequently family has withdrawn the care.

The autopsy showed severe intravascular pulmonary talcosis with numerous perivascular deposits of refractile crystalline material with associated multinucleated giant cell reaction, eosinophilic infiltrates, fibrosis and vascular occlusion. There were also many intravascular crystalline particles entrapped within fresh thrombus material. Some of the larger vessels showed complete luminal occlusion with

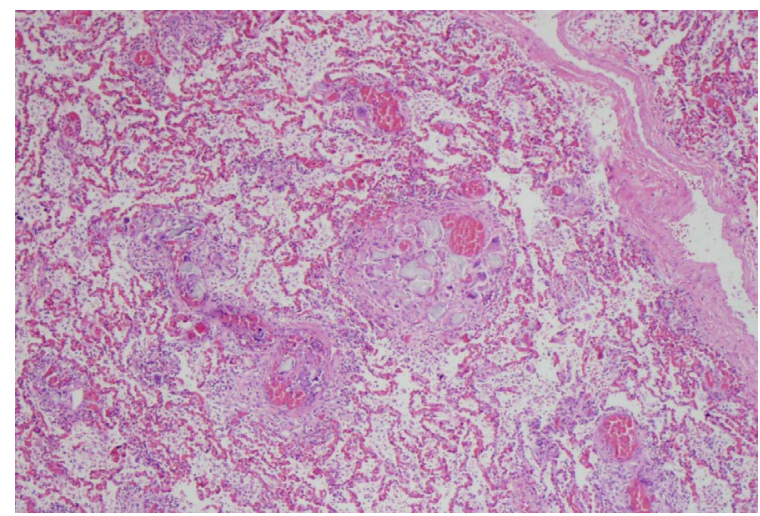

Figure 1: Low-power microscopic field showing refractile material in the pulmonary vessels. The vessels are partly occluded and show recanalization.

${ }^{*}$ Corresponding author: Nandavaram S, State University of New York Upstate Medical University, Syracuse, NY 13202, USA, Tel: +315 350 7332; E-mail: drsnandavaram@gmail.com

Received May 27, 2016; Accepted June 14, 2016; Published June 21, 2016

Citation: Nandavaram S, Chandrasekar VT, Savici D (2016) Acute Pulmonary Vascular Talcosis: Mimicking Acute Pulmonary Embolism. J Vasc Med Surg 4: 272 doi:10.4172/2329-6925.1000272

Copyright: ( 2016 Nandavaram S, et al. This is an open-access article distributed under the terms of the Creative Commons Attribution License, which permits unrestricted use, distribution, and reproduction in any medium, provided the original author and source are credited. 
secondary recanalization. Foreign body giant cell reaction with obliterated pulmonary vasculature was easily seen in every high power field of examined lung sections. The alveoli were filled with fluid and proteinaceous material. Interstitium was expanded and pneumocytes appeared reactive. No obvious bacterial colonies or fungal organisms were seen. There was no evidence of pulmonary embolus. Coronaries were clear (Figure 2).

Our case is unique and different from most of the reported cases in literature, that our patient had severe intravascular pulmonary talcosis leading to acute right heart failure, and was the result of in-hospital drug abuse.

\section{Discussion}

Intravenous injection of powdered tablets intended for oral use is a common practice among drug abusers, given the greater effectiveness attributed to accelerated delivery of the drug through this route compared to oral intake. However, this method not only delivers the drug but also the insoluble filler particles present in the medication. Talc (magnesium trisilicate), methylcellulose, potato starch, and cornstarch are some of the common fillers used in the pills. Following injection, pulmonary vasculature and lung parenchyma act as filter for these insoluble particles [3-10]. Depending on their size, these particles can cause acute embolization, occlude the small vessels and elicit a granulomatous reaction in the vasculature or the parenchyma. Histopathology reveals characteristic foreign body granulomas made up of multinucleated cells containing birefringent needle shaped crystals under polarized light [11-13]. These granulomas can be found in lung interstitium, and result in interstitial fibrosis or in the small pulmonary vessels and result in chronic pulmonary hypertension $[2,3,7]$. Various terms have been used to describe this entity and include self-induced pulmonary granulomatosis, pulmonary angiothrombotic granulomatosis, pulmonary mainline granulomatosis, and angiocentric (or angiothrombotic) systemic granulomatosis $[1,14]$.

Early radiographic changes include a diffuse micronodular pattern, which can gradually coalesce, and progress to heterogenous large opacities with high-density areas and interstitial fibrosis [15-19].

Patients with intravascular or inhalational talcosis can be asymptomatic or may present with fulminant cardiac and respiratory failure. When symptomatic, they usually present with non-specific symptoms such as cough and shortness of breath. Chronic intravenous drug abuse can cause slow progressive symptoms, which may eventually

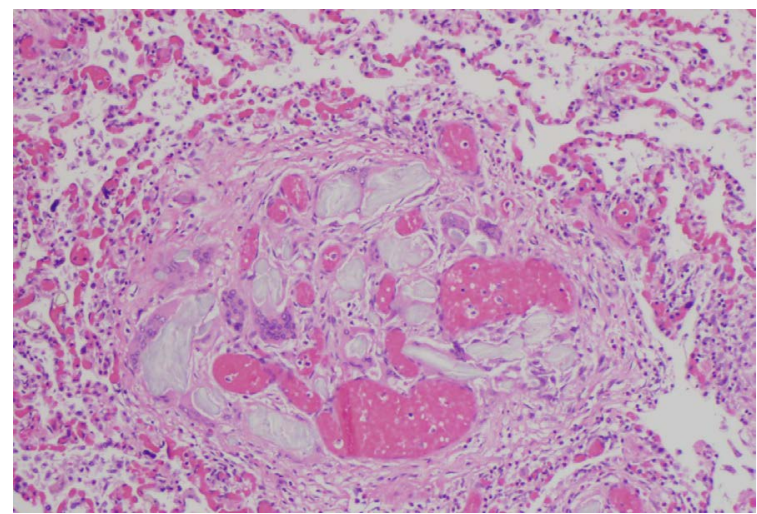

Figure 2: Higher microscopic magnification (100x) showing a recanalized vessel with refractile foreign material and giant cell reaction. result in chronic respiratory failure, emphysema, pulmonary arterial hypertension, and cor pulmonale [20-22]. Intravenous injection of powdered medications can result in acute right ventricular failure secondary to obstructive shock similar to that seen in massive pulmonary embolism. Unfortunately there is no specific treatment in these acute cases, other than supportive care [5]. There are studies, which assessed the immediate pulmonary vascular hemodynamics following intravenous injection of crushed pills. These studies have shown an acute rise in pulmonary arterial pressure, pulmonary vascular resistance and persisted for the following 72 hours, 19 this can explain the acute right ventricular failure and cardiogenic shock observed in these patients.

However, only few such cases were reported in literature and were diagnosed only on autopsy. Autopsy studies in such patients revealed cardiac failure with pulmonary edema, cardiac arrhythmia secondary to pulmonary thromboembolus, multisystem organ failure secondary to sepsis, pulmonary fibrosis, and cardiopulmonary decompensation from pulmonary hypertension as the causes of death [2]. They were found to have increased lung weights and heart weight and dilatation of both right and left heart along with hepatomegaly and splenomegaly.

Though controversial, there have been reports in literature wherein, patients with intravascular talcosis and chronic pulmonary symptoms underwent lung transplantation however on long-term follow up, patients had recurrences, believed to be secondary to relapse of their drug abuse $[15,23]$

\section{Conclusion}

Though hospital is considered as a safe and secure place, possibility of intravenous drug abuse especially in patients with PICC lines while on ambulatory ward should be considered, especially in someone with unexplained hemodynamic collapse with history of intravenous drug abuse [4]. Deaths in such patients should be reported to coroner.

\section{References}

1. Bijaya S, Jerri ML, Matthew MC (2013) Sudden Death by Acute Cor Pulmonale From Intravenous Drug Abuse During an Inpatient Admission: Implications for Unexplained In-Hospital Death. Clinical Pulmonary Medicine 20: 192-195.

2. Griffith CC, Raval JS, Nichols L (2012) Intravascular Talcosis due to Intravenous Drug Use Is an under recognized Cause of Pulmonary Hypertension. Pulmonary Medicine.

3. Roberts WC (2002) pulmonary talc granulomas, pulmonary fibrosis, and pulmonary hypertension resulting from intravenous injection of talc-containing drugs intended for oral use. Baylor University Medical Center Proceedings 15 260-261.

4. Kahn J (2008) A cloud of smoke: The complicated death of a 9/11 hero. The New Yorker.

5. Marchiori E, Lourenço S, Gasparetto TD, Zanetti G, Mano CM, et al. (2010) Pulmonary talcosis: imaging findings. Lung 188: 165-171.

6. Nam K, Gracey DR (1972) Pulmonary talcosis from cosmetic talcum powder. JAMA 221: 492-493.

7. Gibbs AE, Pooley FD, Griffiths DM, Mitha R, Craighead JE, et al. (1992) Talc pneumoconiosis: a pathologic and mineralogic study. Hum Pathol 23: 1344 1354.

8. Feigin DS (1986) Talc: understanding its manifestations in the chest. AJR Am J Roentgenol 146: 295-301.

9. Marchiori E, Souza AS Jr, Franquet T, Müller NL (2005) Diffuse highattenuation pulmonary abnormalities: a pattern-oriented diagnostic approach on high-resolution CT. AJR Am J Roentgenol 184: 273-282.

10. Sussman S, Pentz MA, Spruijt-Metz D, Miller T (2006) Misuse of "study drugs:" prevalence, consequences, and implications for policy. Subst Abuse Treat Prev Policy 1: 15 
Citation: Nandavaram S, Chandrasekar VT, Savici D (2016) Acute Pulmonary Vascular Talcosis: Mimicking Acute Pulmonary Embolism. J Vasc Med Surg 4: 272. doi:10.4172/2329-6925.1000272

11. Iqbal A, Aggarwal B, Menon B, Kulshreshtha R (2008) Talc granulomatosis mimicking sarcoidosis. Singapore Med J 49: e168-170.

12. Cruthirds TP, Cole FH, Paul RN (1977) Pulmonary talcosis as a result of massive aspiration of baby powder. South Med J 70: 626-628.

13. Ward S, Heyneman LE, Reittner P, Kazerooni EA, Godwin JD, et al. (2000) Talcosis associated with IV abuse of oral medications: CT findings. AJR Am J Roentgenol 174: 789-793.

14. Low SE, Nicol A (2006) Talc induced pulmonary granulomatosis. J Clin Pathol 59: 223.

15. Cook RC, Fradet G, English JC, Soos J, Müller NL, et al. (1998) Recurrence of intravenous talc granulomatosis following single lung transplantation. Can Respir J 5: 511-514.

16. Pare JP, Cote G, Fraser RS (1989) Long-term follow-up of drug abusers with intravenous talcosis. Am Rev Respir Dis 139: 233-241.

17. Krimsky WS, Dhand S (2008) Pulmonary talc granulomatosis mimicking malignant disease 30 years after last exposure: a case report. J Med Case Rep 2: 225.
18. Caceres M, Braud R, Garrett HE Jr (2009) An unusual presentation of spontaneous pneumothorax secondary to talc-induced pulmonary granulomatosis. Ann Thorac Surg 87: 1941-1943.

19. Farber HW, Falls R, Glauser FL (1981) Transient pulmonary hypertension from the intravenous injection of crushed, suspended pentazocine tablets. Chest 80 178-182.

20. Stern EJ, Frank MS, Schmutz JF, Glenny RW, Schmidt RA, et al. (1994) Panlobular pulmonary emphysema caused by i.v. injection of methylphenidate (Ritalin): findings on chest radiographs and CT scans. AJR Am J Roentgenol 162: $555-560$

21. Gysbrechts C, Michiels E, Verbeken E, Verschakelen J, Dinsdale D, et al. (1998) Interstitial lung disease more than 40 years after a 5 year occupational exposure to talc. Eur Respir J 11: 1412-1415.

22. Padley SP, Adler BD, Staples CA, Miller RR, Müller NL (1993) Pulmonary talcosis: CT findings in three cases. Radiology 186: 125-127.

23. Shlomi D, Shitrit D, Bendayan D, Sahar G, Shechtman Y, et al. (2008) Successful lung transplantation for talcosis secondary to intravenous abuse of oral drug. Int J Chron Obstruct Pulmon Dis 3: 327-330. 